\title{
ACELERAÇÃO E PERDA
}

por Harry Pross ${ }^{1}$

Traduzido por Norval Baitello Jr.

Resumo/Abstract: Não foi a declaração dos direitos do homem e do cidadão nas revoluções de 1776 e 1789 que determinaram os avanços e recuos da revolução mundial na qual vivemos hoje. Foi a patente da máquina a vapor de James Watt em 1769 e a teoria do teólogo escocês da moral Adam Smith sobre a riqueza das Nações de 1776. O invento técnico e a teoria da riqueza se complementavam. Logo se falava de uma locomotiva do progresso. A palavra locomotiva representava a força da aceleração, a palavra progresso significava 'pro-fit', obter ganhos. Assim também o espírito do nosso tempo, no qual há muito as locomotivas não são o meio de locomoção mais veloz. Os aparatos elétricos controlam ciberneticamente a locomoção e o trânsito. A indústria da mídia e da comunicação são das mais rentáveis. Suas inovações atraem capital de risco e botam milhões de pessoas na rua quando a especulação não resulta em ganhos exorbitantes, tal qual nos mostra a atual crise mundial da economia.

${ }^{1}$ Harry Pross é professor doutor emérito da Universidade Livre de Berlim, Alemanha, e membro do Conselho Científico Consultivo da Revista Ghrebh-. 
"E quantos novos ideais no fundo ainda são possíveis! -- Eis um pequeno ideal: que a cada cinco semanas eu faça um passeio por paragens virgens e solitárias, no momento celestial de uma felicidade sacrílega. Passar a vida entre coisas delicadas e absurdas, alheio à realidade; meio artista, meio pássaro e metafísico; sem dizer sim ou não à realidade, a menos que ela seja reconhecida aqui a acolá, à maneira de um bom dançarino, com a ponta dos pés; sempre acariciada (gekitzelt) por algum feliz eflúvio solar, estendida e animada até pela melancolia - pois a melancolia mantém a felicidade. Uma pequena cauda de farsa que ainda se pendura no sagrado: isto, como é evidente, é o ideal de um espírito pesado, muito pesado, de um espírito de gravidade. " (Friedrich Niezstche)

O espírito do nosso tempo se alimenta da revolução mundial na qual vivemos; mas este espírito não é revolucionário. Falta a ele a enorme força espiritual que se estancou desde o fim da idade média européia, com a impressão do livro e a herança do sistema numérico árabe, para, no iluminismo, explodir as molduras do velho mundo. Caracterizam o espírito do nosso tempo os resíduos daqueles séculos, de suas contradições, fragmentos, pedaços. Eles não se deixam compor em nenhuma imagem. A esperança da arte européia em 1900 era extrair da confusão dos sinais as cifras de um mundo novo, muito novo. Esperança que não se realizou.

Onde a liberdade da arte se associou à revolução política para mudar as relações de poderio, ela fracassou. Revoluções do século XX permaneceram para trás de suas metas. Nenhuma reverteu as condições sociais. Nenhuma criou o novo homem. Não faltaram 
crises, não faltou coragem, nem convicção nem disposição para o sacrifício. Faltou a atuação conjuntas das forças.

\section{II}

Isto era diferente no fim do século XVIII. Naquela época coincidiam as "revoluzione", insurreições populares na Europa ocidental, com os interesses dos colonialistas britânicos na América do Norte. Eles queriam libertar-se das aduanas da pátria-mãe. A mensagem dos direitos civis e humanos atravessou o oceano. Aos olhos de hoje aparentam o evento francês e o americano como uma revolução comum porque ambos prometiam proteger a dignidade e a liberdade do homem.

Que essa promessa não tenha sido cumprida sempre e em toda parte, temos exemplos suficiente no nosso tempo, pois fazem parte da liberdade e da dignidade dos seres humanos outros seres humanos que os reconhecem ou não, e o reconhecimento necessita da vontade de justiça e não apenas a execução das formalidades de uma constituição. Toda constituição documenta o espírito da minoria que a criou para si, para retirar proveitos da maioria. As cores e brasões das bandeiras nacionais sinalizam as origens, a divisão entre ricos e pobres fornecem atualmente o balanço da justiça. A revolução americana foi dos latifundiários e advogados, a francesa foi uma sublevação do povo miúdo e dos ideólogos, que somente foi transformada em código civil pelo oficial de baixa patente Napoleão I.

\section{III}

Estados são instituições de direito com monopólio da violência dentro das fronteiras territoriais. Nem as ambições formais, nem a potência dos recursos de violência estatal dão suficiente informação sobre a maneira como as minorias lidam com as maiorias, os 
fortes com os fracos e as injustiças dos conteúdos desiguais em forma de estado. Nos EUA o postulado dos direitos humanos de 1776 era perfeitamente compatível com a escravidão até a vitória dos estados do norte industrializados na guerra civil em 1865. a escravidão era muito mais uma questão econômica que humanitária, de dignidade do homem.

Todo estrado enfeixa força e fraqueza em sua contradição com justiça e polícia, mas não nas suas relações de posse. Em todo estado as minorias se nutrem da força de trabalho das maiorias. Por isso falem os regimes capitalista tanto quanto comunista em seu território circunscrito, quando perdem o respaldo das massas condescendentes. Manter as massas de bom humor é a meta de ditaduras como democracias.

No nosso tempo terei que voltar a este ponto de vista no tópico "globalização". Antes disso algumas palavras sobre as causas da aceleração e suas conseqüências. Elas são de natureza técnica e ideológica.

\section{IV}

Não foi a declaração dos direitos do homem e do cidadão nas revoluções de 1776 e 1789 que determinaram os avanços e recuos da revolução mundial na qual vivemos hoje. Foi a patente da máquina a vapor de James Watt em 1769 e a teoria do teólogo escocês da moral Adam Smith sobre a riqueza das Nações de 1776.

O invento técnico e a teoria da riqueza se complementavam. Logo se falava de uma locomotiva do progresso. A palavra locomotiva representava a força da aceleração, a palavra progresso significava 'pro-fit', obter ganhos. Assim também o espírito do nosso tempo, no qual há muito as locomotivas não são o meio de locomoção mais veloz. Os aparatos elétricos controlam ciberneticamente a locomoção e o trânsito. A indústria da 
mídia e da comunicação são das mais rentáveis. Suas inovações atraem capital de risco e botam milhões de pessoas na rua quando a especulação não resulta em ganhos exorbitantes, tal qual nos mostra a atual crise mundial da economia.

Mas foi a máquina a vapor que há duzentos anos transformou a aceleração em base da existência social. Por isso o espírito do nosso tempo se evapora em desvario quando perde alguma coisa. Há um século o medo de perder algo produziu o homem nervoso. 0 filósofo Nietzsche (e outros) o descreveram. A Psicanálise tenta, desde então, tratá-lo, pois o medo de perder força a pressa até o ritmo assassino. Os apressados segregam os outros e constroem com isso falsos conceitos de seu meio ambiente. Este Ihes parece decadente, mas são eles os decadentes.

O equívoco é determinado biológica e psicologicamente: todo ser humano, grande ou pequeno, velho ou jovem, mulher ou homem, só pode estar em um lugar e não em todos os lugares ao mesmo tempo. Seus nervos se concentram em uma necessidade. Sua tensão se distende quando a meta está atingida. Metas pendentes sobrecarregam a psique como ações inacabadas. Pendências deprimem. A palavra de moda é estresse que quer dizer pressão. Mas as depressões paralisam a capacidade de ação: estresse vira estagnação. A bandeira do progresso acena na frente do ciclo da depressão dos homens e dos sistemas. Também isso é o espírito do nosso tempo.

\section{V}

O medo individual de perder algo e o fato coletivo da aceleração nasceram do incremento de todos os meios de transporte que já Marx/Engels em 1848 destacaram em seu Manifesto Comunista, tal qual o grande êxito político e econômico da classe burguesa. 
Depois de Adam Smith a divisão da força de trabalho em conformidade com o mercado é a chave do sucesso econômico. O monopólio de compra do capital no mercado de trabalho em concorrência com outros detentores de capital tem que se utilizado rapidamente para ocupar territórios pobres em capital. O capital foge onde não há rendimentos. Ele procura trabalho barato para receber de volta os salários desgastados por via da força de compra do mercado.

Assim o estresse individual de 2002 é uma conseqüência das "comunicações infinitamente facilitadas" de 1848, reforçadas pela simbiose entre sociedades eletrificadas, sistema bancário em torno de 1900 e aceleração do transporte da informação por meio das transmissões globais do século XX.

Mas elas não fazem uma "aldeia global" e nós não nos divertimos pra morrer, mas nos frustramos, cada um em seu canto, pois ninguém pode se enfurecer fora da própria pele. Quando duas pessoas se encontram, já é muito. Quando dormem juntas, se aquecem, como já observara o rei bíblico Salomão com sua pergunta "Como pode uma pessoa sozinha se aquecer?" Os mais pobres se aquecem nos seus cachorros.

Expressões fantasmas como "aldeia global" ou "divertimento pra morrer" fazem parte do vocabulário da propaganda da política e da economia para manter bem dispostas as massas condescendentes. O interesse comum de estado e economia em transformar as frustrações, a renúncia e a decepção em novas expectativas, produziu uma ciência para este fim, cujas origens remontam à antiguidade e reanimam práticas mitológicas.

\section{VI}

O sentimento que o nosso tempo do calendário não combina com o nosso tempo de vida individual não espanta diante de uma população de seis bilhões de pessoas. Por que afinal 
deveriam culturas muito mais antigas viver na contagem cristã do tempo? Elas tem que se atritar entre si nas comunicações infinitamente facilitadas porque todo aparato técnico, toda roupa diferente, todo produto cultural complexifica as coisas humanas reais.

As formas de comunicação estão mundialmente mutiladas. Isto é o mais seguro que se pode dizer a respeito da globalização, mesmo quando multinacionais anunciam sua chegada no mercado com marcas e logotipos, como o faziam os missionários com seus símbolos religiosos e os estados com suas bandeiras. E, se tiver que ser, até mesmo sobre a lua.

Interesses estatais e econômicos intensificaram a aceleração até a velocidade de hoje. O mercado financeiro ganhou a prioridade por meio dos inventos da técnica de comunicação. O ritmo dos negócios das bolsas de valores direciona hoje o medo pelo emprego tal qual o compasso das máquinas na era da máquina a vapor. Em regiões inteiras apagam-se as luzes porque em algum confim uma empresa não registra lucros.

Governos maquiam o fato de não controlarem o mercado de trabalho de seus paises, nem garantirem o curso de suas moedas. Mafiosos se aproveitam da impotência para formar um patrimônio extraordinário. A corrupção estatal abre alas para as instituições do nãodireito, da injustiça. As regras internacionais de uma ordem mundial da ONU e de outras organizações se deparam com a resistência norte-americana.

Apesar de tudo, o critério do bioquímico recém falecido Erwin Chargaff continua correto: Não temos nada a perder se julgarmos o espírito de nosso tempo por um triplo critério: "Como um povo cuida de suas crianças, como ele lida com seus velhos e como ele trata suas árvores." 
BAITELLO JR., NORVAL, (1997) O animal que parou os relógios. São Paulo: Annablume

BAUDRILLARD, JEAN, (2001) A ilusão vital. R. de Janeiro: Civilização Brasileira

CASTRO e outros (orgs.), GUSTAVO DE, (1997) Ensaios de complexidade. Porto Alegre:

Sulina

CONTRERA, MALENA S., (2002) Mídia e pânico - saturação da informação, violência e crise cultural na mídia São Paulo: Annablume

HILLMAN, JAMES, (1993) Paranóia Petrópolis: Vozes

MAFFESOLI, MICHEL, (1996) No fundo das aparências. Petrópolis: Vozes

MARCONDES FILHO, CIRO, (2000) A saga dos cães perdidos. São Paulo: Hacker

MORIN, EDGAR, (1988) O paradigma perdido. Lisboa: Europa-América

MORIN, EDGAR, (1992) O método IV. Lisboa: Europa-América

SERRES, MICHEL, (1995) A comunicação. Porto: Rés

SERRES, MICHEL, (1995) A lenda dos anjos. São Paulo: Aleph

SERVA, LEÃO, (2000) Jornalismo e desinformação. São Paulo: Senac

SODRÉ, MUNIZ e PAIVA, RAQUEL, (2002) O império do grotesco. Rio de Janeiro: MAUAD

TASCHNER, GISELA, (1992) Folhas ao vento - uma análise de um conglomerado jornalístico no Brasil. São Paulo: Paz e Terra 